RAND RESEARCH AREAS

THE ARTS

CHILD POLICY

CIVIL JUSTICE

EDUCATION

ENERGY AND ENVIRONMENT HEALTH AND HEALTH CARE INTERNATIONAL AFFAIRS NATIONAL SECURITY POPULATION AND AGING PUBLIC SAFETY SCIENCE AND TECHNOLOGY SUBSTANCE ABUSE TERRORISM AND HOMELAND SECURITY TRANSPORTATION AND INFRASTRUCTURE

This product is part of the RAND Corporation research brief series. RAND research briefs present policy-oriented summaries of published, peer-reviewed documents.

Headquarters Campus 1776 Main Street P.O. Box 2138

Santa Monica, California 90407-2138

TEL 310.393 .0411 FAX 310.393 .4818

() RAND 2009

\title{
Assessing Parolees' Health Care Needs and Potential Access to Health Care Services in California
}

0 ver the past 20 years, the number of individuals released from California prisons has increased nearly threefold, and most of the state's prisoners ultimately will return to California communities, bringing with them a variety of health and social needs that must be addressed. This raises key public health challenges, especially because ex-prisoners are returning to communities whose safety nets are already severely strained. To address these challenges, policymakers need to better understand the health care needs of individuals returning from prisons and the corresponding capacity of the health care safety net in the communities to which they return.

This report addressed three research questions: (1) what are the health care needs of prisoners in California upon their release; (2) what is the geographic distribution of state prisoners who return to local communities in California; and (3) what types of health care, mental health, and substance abuse services are available in these communities, and what is their capacity to meet the needs of returning prisoners?

\section{Health Care Needs Are High, but Mental Health and Drug Treatment Needs Are Even Higher}

Using a state-level analysis of California data from a national survey of state prison inmates, RAND researchers found that such inmates bear a high burden of chronic diseases, such as asthma and hypertension, as well as infectious diseases, such as hepatitis and tuberculosis - conditions that require regular use of health care for effective management. Among inmates who reported a current medical issue, most reported seeing a physician since admission to prison. However, according to the literature on the subject, the likelihood of receiving health care upon release seems low, given barriers to accessing care and obtaining health insurance. Thus, ex-prisoners returning to communities bring

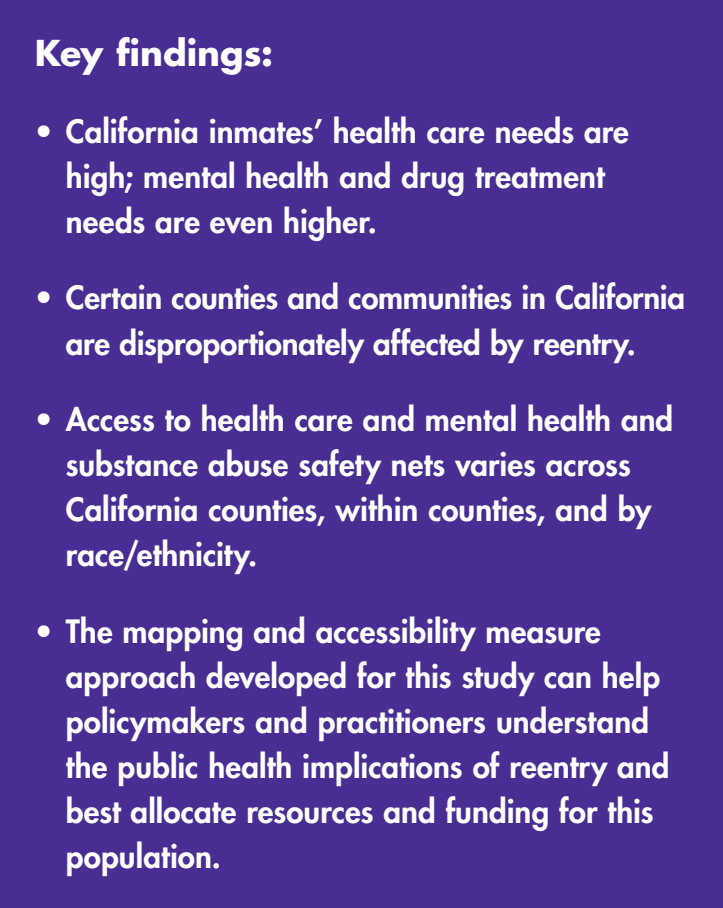

a host of unmet health needs and will depend on counties' abilities to meet those needs.

Drug treatment and mental health care needs are even more pronounced. About two-thirds of California inmates reported having a drug abuse or dependence problem, but only 22 percent of those inmates reported receiving treatment since admission to prison. More than half of California inmates reported a recent mental health problem, with about half of those reporting receiving treatment in prison. Given the high prevalence of these problems among the prison population, parolees' need for services in communities may be particularly high.

\section{Certain Counties and Communities Are Disproportionately Affected by Reentry} The study relied on geocoded corrections data for parolees released from California state prisons in 
2005-2006 and cluster analysis to examine the geographic distribution of parolees and to identify concentrations of parolees across and within counties. The findings show that certain counties have higher rates of return and that, within counties, there are distinct clusters of parolees. This result has implications in terms of targeting reentry resources to these areas. Although the analysis showed concentrations statewide, the study focused on four counties that received one-third of the total parolees: Alameda, Kern, Los Angeles, and San Diego.

In Alameda County, almost 45 percent of the returning parolee population is concentrated in five distinct clusters, primarily around Oakland and the northern section of the county. In Kern County, there are four distinct clusters of parolees, with concentrations around the urban area of Bakersfield and two other areas in the northern and northeastern sections of the county; these clusters account for almost 58 percent of parolees. In San Diego County, there are eight clusters that account for nearly half the parolee population, with the largest clusters in Downtown San Diego and Southeast San Diego. Unlike in the other counties, Los Angeles County has 23 distinct clusters of parolees covering a large geographic area but accounting for only 35 percent of the total county parolees. This dispersion suggests that providing services to the reentry population requires a targeted approach within the various supervisorial districts and service planning areas (SPAs).

Analysis also shows that, in California, African-American and Latino parolees, in particular, tend to return to disadvantaged neighborhoods and communities, defined by high poverty rates, high unemployment rates, and low educational attainment.

\section{Access to Safety-Net Resources Varies Substantially}

The study drew on facility data for hospitals, clinics, mental health services, and substance abuse services to characterize the respective safety nets that serve the uninsured and the parolee population in the four chosen counties. The findings show that parolees' access to health care resources varies by facility type (hospitals, clinics, mental health services, and alcohol and drug treatment services), by geographic area (across and within counties), and by race/ethnicity. One issue that stands out in the three large urban counties-Alameda, Los Angeles, and San Diego-is that most parolees reside in areas with the lowest levels of accessibility to general acute care hospitals, with Alameda County having the largest share of parolees in areas with the lowest levels of accessibility. In all the counties, community clinics appear to play an important role in filling gaps in coverage by medically indigent service providers (MISPs) vis-à-vis the reentry population.
Still, the findings for all four counties reveal that some important geographic gaps in access to health care resources remain, given the distribution of parolees. Some of the most prominent gaps appear in Los Angeles County (as shown in the figure), where certain supervisorial districts with high concentrations of parolees (shown in the darkest shade of blue) have sparse hospital and clinic resources, including MISP hospitals, other general acute care hospitals and other public hospitals (shown as other hospitals), MISP clinics, and other primary care and public-private partnership clinics (shown as other clinics). The most striking gaps are in District 2, which covers the area called Southern Los Angeles and includes Martin Luther King/Charles R. Drew Medical Hospital (shown as the star), which closed in 2005.

To determine accessibility to health care resources, the RAND researchers developed measures based on capacity, demand, and distance. Capacity was measured by using fulltime equivalents (FTEs) for facilities, when available, and the assessment of demand accounted for the fact that parolees are not the only populations drawing on these facilities. Distance was measured in terms of a 10-minute drive time to facilities, assuming that this population would be less mobile and more reliant on public transportation.

The table shows an example of hospital accessibility for Los Angeles County. Overall, more than half of the parolees reside in areas with either the lowest or mid-lowest levels of accessibility to hospitals; there is also variation by parolees' race/ethnicity. For example, in terms of accessibility to hospitals in Los Angeles County, more African-American parolees live in areas with lower accessibility than do Latino or white parolees. By way of comparison, Alameda County has a similar pattern, but in Kern and San Diego counties, more Latino parolees reside in areas with lower accessibility to hospitals than do white and African-American parolees (not shown).

With regard to mental health resources, a larger share of parolees in Kern and San Diego counties live in areas with the two lowest levels of accessibility than do parolees in Alameda and Los Angeles counties. In terms of accessibility to alcohol- and drug-treatment providers, the opposite is true. Only about a third of parolees in Kern and San Diego counties live in areas with the two lowest levels of accessibility, compared with between 42 and 44 percent of parolees in Alameda and Los Angeles counties, respectively.

Accessibility to mental health care and alcohol- and drug-treatment resources also varies by race/ethnicity. For example, in Kern and San Diego counties, roughly 84 percent of African-American parolees live in areas with higher accessibility to alcohol- and drug-treatment resources, compared with only 60-65 percent of Latino and white parolees. In Los Angeles County, about 50 percent of African-American and Latino parolees and 60 percent of white parolees live in areas 
Gap Between Parolee Concentrations and Health Care Resources: Southern Los Angeles County

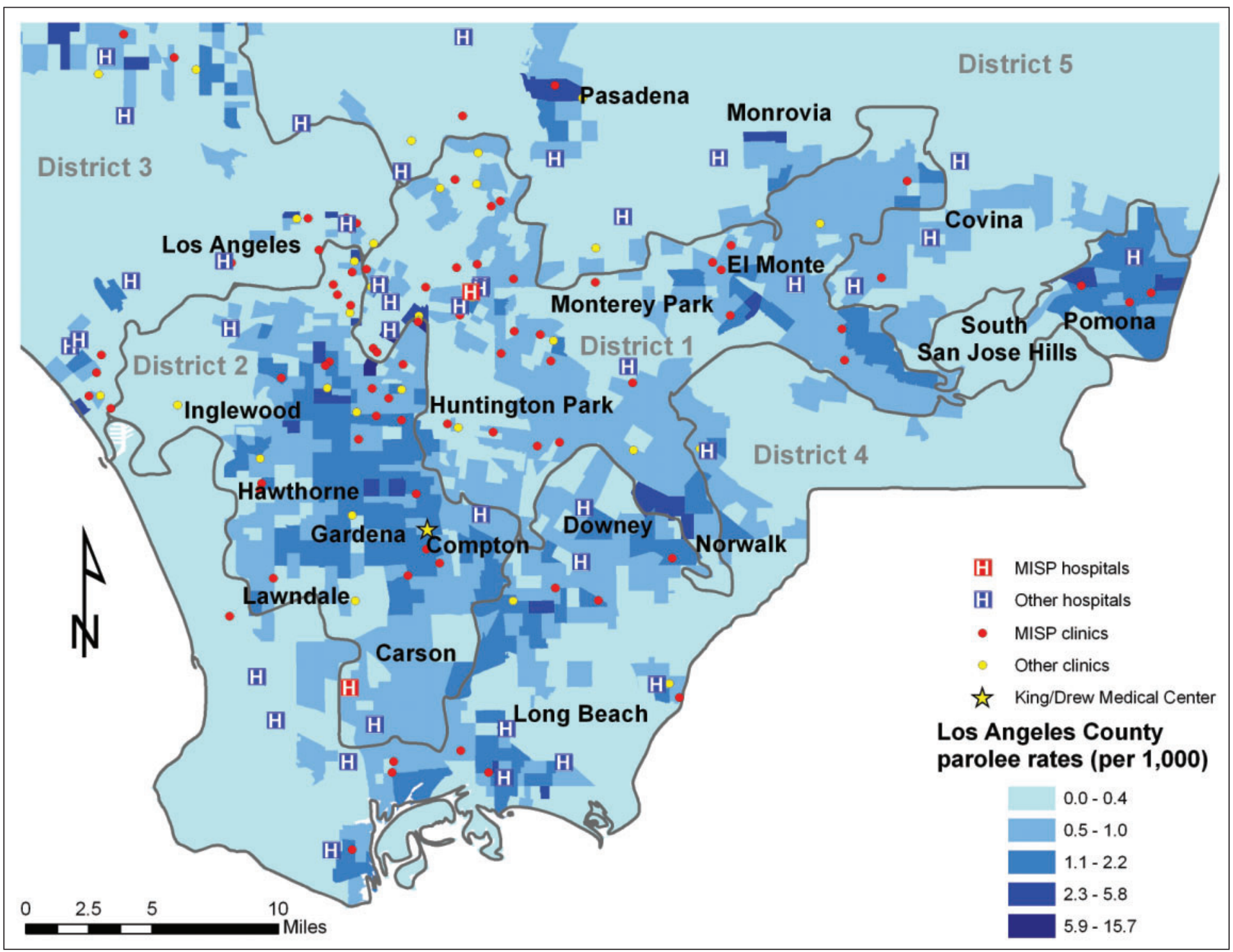

Distribution of Parolees (Percent) Across Hospital Accessibility Levels: Los Angeles County

\begin{tabular}{|c|c|c|c|c|}
\hline $\begin{array}{l}\text { Level of Accessibility to } \\
\text { Hospitals }\end{array}$ & $\begin{array}{l}\text { All Parolees } \\
(\mathrm{n}=35,710)\end{array}$ & $\begin{array}{l}\text { African-American Parolees } \\
\qquad(\mathrm{n}=12,885)\end{array}$ & $\begin{array}{l}\text { Latino Parolees } \\
\quad(n=14,921)\end{array}$ & $\begin{array}{l}\text { White Parolees } \\
\qquad(\mathrm{n}=6,671)\end{array}$ \\
\hline Lowest accessibility & 24 & 29 & 21 & 24 \\
\hline Mid-low accessibility & 29 & 31 & 30 & 23 \\
\hline Mid-high accessibility & 30 & 25 & 33 & 30 \\
\hline Highest accessibility & 17 & 15 & 16 & 23 \\
\hline Total & 100 & 100 & 100 & 100 \\
\hline
\end{tabular}

with higher accessibility. In Alameda County, there are smaller differences in accessibility to these resources by race/ethnicity.

For mental health care and drug and alcohol treatment, separate networks provide services to the parolee population and serve as the initial safety net for them. But both networks have very limited capacity, suggesting that many parolees may not be receiving these services and that most of the reentry population must rely instead on treatment resources available to the uninsured and low-income populations in a county. 


\section{Implications}

The analysis of the distribution and concentration of parolees in California showed that there are distinct clusters across the state and that, within counties, parolees tend to cluster in certain communities and neighborhoods. Such clustering has implications for developing strategies to provide health care services and other resources to parolees and to better link this population to needed services. That parolees in more rural counties tend to be more dispersed suggests that a different strategy for providing health care services to these individuals is needed. Also, Los Angeles County (with the largest proportion of parolees) is a combination of both urban and more sparsely populated areas. The county's large number of distinct parolee clusters cover a broad geographic area. This suggests the need to tailor strategies for providing services to the parolee population by supervisorial district and SPA.

In addition, the fact that African-American and Latino parolees, in particular, tend to return to disadvantaged neighborhoods and communities suggests that reentry in these communities will be even more challenging because the parolees' needs for health care, housing, employment, and other services will be harder to meet.

Furthermore, because community clinics play a large role in filling geographic gaps in the safety net, one strategy to improve the level of accessibility in areas with high concentrations of parolees would be to fund more community clinics. Then again, in the current economic crisis, safetynet providers will become even more stressed. As California considers options for reducing correctional costs by releasing more parolees or offenders without conditions of parole, it is important to assess the health care impact of these decisions. Community clinics and hospitals, particularly in areas with high concentrations of parolees and where few other community resources exist, will be especially affected.

There is also a need to consider how to better integrate the different networks of substance abuse treatment services and assess where greater investments may be needed. Investing in improving access to these services in communities where parolees are concentrated may yield long-term benefits when it comes to improving the chances of successful reentry, including positive treatment and criminal justice outcomes. Policymakers may also consider ways to improve access to county alcohol- and drug-treatment services.

Like the substance abuse safety net, the mental health one comprises a patchwork of networks. Parole Outpatient Clinics (POCs) are an important initial source of mental health care for parolees and, at least in one of the four focus counties, serve as the gatekeeper to accessing county mental health services. Coupled with prerelease assessments, POCs have been shown to contribute to lower recidivism rates among mentally ill offenders. However, the study found that there are relatively few POCs in the four counties and that many parolees have to travel far to access these services. Further, anecdotal information suggests that some POCs may see cutbacks in staffing, given the current economic crisis.

It is also important to assess policy and institutional barriers that may prevent access to needed services. One area worth assessing is the POC gatekeeper role. From a health services perspective, this may undermine parolee reentry efforts, because some POCs are understaffed and have long waiting lists. Also, anecdotally, it appears that parolees have a strong disincentive to report mental health problems to their parole officer for fear of being considered at high risk of recidivism. These types of policy and institutional barriers will be examined in more depth in the study's second phase.

Finally, beyond these specific research-related implications, the approach of mapping parolee clusters in the context of the safety net and accessibility to health care resources is an important step, not only in helping policymakers and practitioners understand the public health implications of reentry, but also in helping them best allocate and fund resources for this population. These measures provide an indication of how potential access to safety-net resources varies within each county for the parolee population. The approach to measuring accessibility was independently validated by comparing how well the measures correlated with measures of medically underserved areas and populations in California. These results provide confidence that the measures are robust and can serve as a useful planning tool.

\footnotetext{
This research highlight describes work done for RAND Health and RAND Infrastructure, Safety, and Environment documented in Understanding the Public Health Implications of Prisoner Reentry in California: Phase I Report, by Lois M. Davis, Nancy Nicosia, Adrian Overton, Lisa Miyashiro, Kathryn Pitkin Derose, Terry Fain, Susan Turner, Paul Steinberg, and Eugene Williams III, TR-687-TCE (available at http://www.rand.org/pubs/technical_reports/TR687/), 2009, 218 pp. This research highlight was written by Paul Steinberg. The RAND Corporation is a nonprofit research organization providing objective analysis and effective solutions that address the challenges facing the public and private sectors around the world. RAND's publications do not necessarily reflect the opinions of its research clients and sponsors. RAND ${ }^{\circledR}$ is a registered trademark.
} 


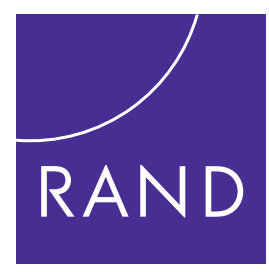

HEALTH and INFRASTRUCTURE, SAFETY, AND ENVIRONMENT

THE ARTS

CHILD POLICY

CIVIL JUSTICE

EDUCATION

ENERGY AND ENVIRONMENT

HEALTH AND HEALTH CARE

INTERNATIONAL AFFAIRS

NATIONAL SECURITY

POPULATION AND AGING

PUBLIC SAFETY

SCIENCE AND TECHNOLOGY

SUBSTANCE ABUSE

TERRORISM AND HOMELAND SECURITY

TRANSPORTATION AND INFRASTRUCTURE

WORKFORCE AND WORKPLACE
This PDF document was made available from www.rand.org as a public service of the RAND Corporation.

This product is part of the RAND Corporation research brief series. RAND research briefs present policy-oriented summaries of individual published, peerreviewed documents or of a body of published work.

The RAND Corporation is a nonprofit research organization providing objective analysis and effective solutions that address the challenges facing the public and private sectors around the world.

\section{Support RAND}

$\underline{\text { Browse Books \& Publications }}$

Make a charitable contribution

\section{For More Information}

\author{
Visit RAND at www.rand.org \\ Explore RAND Health \\ Infrastructure, Safety, and Environment
}

View document details

\section{Limited Electronic Distribution Rights}

This document and trademark $(s)$ contained herein are protected by law as indicated in a notice appearing later in this work. This electronic representation of RAND intellectual property is provided for non-commercial use only. Unauthorized posting of RAND PDFs to a non-RAND Web site is prohibited. RAND PDFs are protected under copyright law. Permission is required from RAND to reproduce, or reuse in another form, any of our research documents for commercial use. For information on reprint and linking permissions, please see RAND Permissions. 